Prostate cancer is one of most frequent malignant tumours at men. The androgen-deprivation therapy is the part of cancer treatment. It could be used both in the early stage of prostate cancer and in the bone metastates. From this reason the antiandrogen drugs waste systematically grows. Unfortunately androgen-deprivation therapy has numerous side effects such as: the inferior quality of live, sexual disturbances, the fatigue, the anaemia, the bone mineral density loss and the increase of the risk of breaks the bone, the increase of body mass, insulinresistance, hypercholesterolemia, the increase risk of cardiac disorders. The aim of this article is the introduction of the reader with possibly complications androgen-deprivation therapy and with possibilities in diagnosis and treatment.

Key words: prostate cancer, androgen deprivation therapy, side effects.

\section{The side effects of hormonal therapy at the patients with prostate cancer}

\author{
Ewa Ziółkowska ${ }^{1}$, Małgorzata Zarzycka ${ }^{1}$, Tomasz Wiśniewski ${ }^{12}$, \\ Agnieszka Żyromska ${ }^{3}$
}

1Department of Radiotherapy I, Oncology Centre - prof. Franciszek Łukaszczyk Memorial Hospital, Bydgoszcz, Poland

${ }^{2}$ Chair and Clinic of Oncology and Brachytherapy, L. Rydygier Collegium Medicum in Bydgoszcz, Nicolaus Copernicus University in Torun, Poland

${ }^{3}$ Department of Teleradiotherapy, Oncology Centre - prof. Franciszek Łukaszczyk

Memorial Hospital, Bydgoszcz, Poland

\section{Introduction}

Prostate gland cancer is the second most frequent malignant tumor in Poland among men and the third most frequent cause of malignancy-related death [1]. It is established that one in two men suffering from prostate tumor will require hormone therapy at some stage of tumor treatment [2].

Hormonal therapy retards progression of the disease, prevents serious complications and alleviates symptoms of prostate cancer. The aim of the treatment is to reduce the access of prostate cancer cells to testosterone. This is achieved in several ways. First, bilateral orchidectomy leads to the fast decrease of testosterone concentration in the blood. The alternative is pharmacological castration, which is done by cyclical administration of analogs or agonists of luteinizing hormone. In turn, the anti-androgenic drugs block androgen receptors in prostate cancer cells. The combination of pharmacological or surgical castration with anti-androgenic treatment leads to so-called maximum androgen blockade. In long-lasting hormonal therapy a treatment involving periodic gaps in treatment after the patient has reached biochemical regression is recommended (intermittent androgen blockade - IAB). Reactivating the hormonal drugs occurs when successive increase in concentration of prostate-specific antigen (PSA) is observed. This type of treatment can reduce the side effects of the applied therapy and delay the appearance of resistance of prostate cancer to hormonal treatment [3]. Many side effects of hormonal therapy are reported: worse quality of life, sexual dysfunctions, fatigue, anemia, decreased bone density and increased risk of fractures, body mass increase, insulin resistance, hypercholesterolemia, and increased risk of heart diseases [4-8]. These symptoms are independent of the method of hormonal therapy (oral or orchidectomy) and result from reduced concentration of testosterone [4-6].

$86 \%$ of men suffering from prostate cancer have a disease limited to the prostate gland. In this group five-year survival rates reach up to 100\% [9]. Patients suffering from prostate cancer die more often for non-cancer reasons, which is partly connected with the detrimental aftermath of oncological treatment. Due to the good prognosis, in the case of patients with early prostate cancer a treatment should not cause side effects that may affect the quality of life more than the disease itself. Anti-androgen monotherapy is currently rarely used, but must be considered in the case of young people with prostate cancer who want to preserve sexual function. This drug does not reduce testosterone concentration in the blood and hence does not adversely affect erection. On the other hand, anti-androgens can cause diarrhea and a hepatotoxic effect. In the case of maximum androgen blockade, the percentage and inten- 
sity of complications (including those involving the stomach, intestine, eyes and hematopoietic system) are larger than in the case of hormonal castration [3]. Intermittent treatment should inherently have a lower risk of complications compared to a continuous hormone therapy. The results of randomized trials aiming to confirm this assumption are expected. The purpose of this article is to present the spectrum of complications of the most commonly used hormonal castration (surgical or medical) and how to effectively prevent and overcome the consequences of this therapy.

\section{Hot flashes}

Described as a sudden and intense feeling of heat in the face, neck and upper body, which lasts from seconds to an hour. They are considered one of the most common and the most troublesome side effects since they appear in more than $80 \%$ of patients with prostate cancer treated with hormonal therapy [10]. Hot flashes are often caused by so-called trigger factors, which include stress, heat, a sudden change in body position, stimulants (coffee, cigarettes, alcohol) and consumption of spicy food [11, 12]. As non-pharmacological measures it is advised to avoid the aforementioned generative triggers, wear clothes made of natural fibers such as linen or cotton, use cold compresses to the neck or drink a glass of cold drink at the onset of symptoms and take regular exercise [11]. If burdensome symptoms keep occurring even after the change of lifestyle according to the recommendations mentioned above, it is advisable to include hormonal drugs: megestrol, cyproterone, nadroxyprogesterone or diethylstilbestrol in low doses. One should remember that these preparations may increase the risk of cardiovascular and thrombotic complications [12, 13]. Of interest to researchers were also new antidepressants, especially citalopram and venlafaxine, but their effectiveness is lower than that of hormonal drugs. Studies to assess the effect of other neuropsychiatric drugs such as gabapentin or clonidine are ongoing [11].

\section{Feeling of tiredness}

It is classified as one of the most common as well as the most difficult to treat side effects of hormonal therapy. Its escalation may be caused by any other complications of hormonal therapy, e.g. anemia or sarcopenia (skeletal muscles mass loss). The best results of tiredness treatment are achieved by changing one's lifestyle and introducing specially designed physical exercises. Recommended non-pharmacological methods include not smoking, avoiding stress or great effort, replacing useless work that may waste the patient's energy with useful work that brings them satisfaction (it stimulates the self-reward mechanism), and avoiding longer than one hour rest in the day time [11]. It is important to balance the time of rest and of activity by resting before the tiredness comes as short breaks are better than a long rest time. It may be helpful to schedule the most important activities during a whole day. Healthy eating and regular physical exercises that prevent the loss of skeletal muscle mass are also crucial [14].

\section{Sexual dysfunctions}

According to American authors, the most frequently reported side effects of hormonal therapy are lack of interest in sexual intercourse and impotence. In Poland, this problem seems not to have been assessed in depth, probably because it is considered a taboo by both patients and doctors. It is therefore very important for doctors to gain patients' trust in order to be able to talk about the aspects that are commonly found embarrassing. What is also important is that the problem affects the patient's wife as well as himself as it requires understanding and cooperation from both of them. It should be explained to the partners that men's lower level of testosterone does not eliminate his sexuality but changes it. The substitution for sexual life may be found in simple gestures such as holding hands, cuddling or caring about the other person in a special way [11]. When it is necessary to introduce pharmacological treatment, the choice is between prostaglandin injections into the cavernous body of the phallus, which are more effective in maintaining the erection, and drugs containing 5-phosphodiesterase inhibitors, which work well, too, although their effectiveness may be decreased when used with hormone therapy as they require androgens to work [13].

\section{Psychological effects}

Usually they are cognitive dysfunctions and concentration and memory deterioration followed by emotional instability and bad mood or even depressive episodes [11, 12]. It should be explained to the patient that these symptoms are temporary and caused by the treatment. Some uncommon serious cases require a psychiatric opinion and specially oriented treatment.

\section{Bone loss and bone fractures}

Some tests showed decrease of bone mass (bone mass density, BMD) and increased risk of bone fractures in cases of patients with prostate gland cancer who were given hormonal drugs $[12,15,16]$. A retrospective study conducted in a group of 50000 patients proved that $18.4 \%$ of patients with prostate gland cancer who underwent hormonal therapy experienced bone fractures while in the group of patients who did not undergo hormonal therapy only $12.6 \%$ experienced bone fractures. The risk of fractures was determined by the treatment intensity and was higher in the case of long-term treatment. Also orchidectomy may cause the risk, which means it is connected with reduction of androgen concentrations in the patient's body and is not determined by the drug's ingredients [17]. Similar results were obtained in a population study which showed that the use of anti-androgenic drugs may increase the risk of bone fractures (HR 1.65; 95\% Cl: 1.53-1.77), and the longer the treatment lasts the higher the risk is [5]. In the Wilcox et al. study performed on a group of 174 patients with prostate cancer treated with hormonal therapy (median duration of treatment was 21 months), 24 patients (14\%) experienced bone fractures. Among them 11 had 1 bone fracture risk factor and 8 had 2 or more other factors (Table 1 ).

The most frequent was fracture of the spine [18]. The percentage of fractures was similar as in other studies, where it was $6 \%$ to $20 \%$ and depended on the observation period 
[19-21]. In a group of healthy men of similar age to the patients, the percentage of bone fractures was 1-2\% per year [19]. Another study conducted on a group of 288 people treated with hormonal therapy showed the percentage of bone fractures as $2.7 \%$ per year, which was 3 times higher than in a control group of 300 people ( $0.7 \%$ per year) [22]. It was also proven that in men with prostate cancer who experience bone fractures overall survival is also lower (121 months compared to 160 months in a group with no bone fractures) [23]. Decrease of bone density in healthy men aged 65-80 is $0-0.6 \%$ per year [6] while after introducing hormonal therapy it grows to $2-5 \%$ per year $[7,19,20]$ and is noticeable as soon as 6 months after the treatment begins [24].

The first method of preventing osteoporosis is non-pharmacological treatment defined by a change of one's lifestyle by giving up smoking and limiting alcohol and coffee. Regular physical exercise is recommended as well as a diet rich in calcium and vitamin D [11]. It was proven that giving up smoking and alcohol is enough to reduce the risk of bone density decrease and bone fracture and regular daily physical exercise (20-45-minute sessions 2-4 times a week) may lead to increase of bone density by $1-2 \%$ [25]. Calcium and vitamin $\mathrm{D}$ deficiency is frequently diagnosed among patients with prostate cancer [26]. When a patient is diagnosed with osteoporosis (T score $<-2.5$ ) it is recommended to include in the treatment vitamin D in the dose of 800-2000 IU/day, and calcium supplementation in the dose of 1200$1500 \mathrm{mg} /$ day because it was proven to lead to a reduction of osteoporosis-caused fractures by $12 \%$ [27]. A few authors suggest that all patients with prostate cancer aged over 65 years should be given vitamin D and calcium [11].

\section{Pharmacological treatment}

\section{Bisphosphonates}

Bisphosphonates should be introduced to the treatment when an osteoporosis-caused fracture occurs or when the T score value drops below 2.5 [11]. They reduce bone resorption by blocking osteoclasts' activity and they prevent cancer treatment-induced bone loss in the case of patients with prostate globe cancer treated with hormone therapy
Table 1. Risk factors of bone fractures

bone fractures in medical history
osteoporosis in the family
low BMI
smoking
excessive alcohol consumption
steroid therapy
low level of vitamin D
duration of hormonal therapy $>6$ months

[25]. However, one should remember about simultaneous calcium and vitamin D supplementation as in the case of lower calcium concentration in the blood the effectiveness of bisphosphonates is decreased [1]. Results of clinical tests evaluating bisphosphonates' effectiveness in preventing bone loss are presented in Table 2.

\section{Estrogens}

Two studies conducted on a sparse population of patients showed a positive impact of small doses of estrogens (diethylstilbestrol $1 \mathrm{mg} / 24 \mathrm{~h}$ or ethinylestradiol $1 \mathrm{mg} / 24 \mathrm{~h}$ ) on concentration of bone resorption markers in patients with prostate cancer treated with hormonal therapy. Unfortunately, the study did not include patients' bone density or frequency of fracture measurements [34, 35]. A disadvantage of estrogen drugs is that they increase the risk of cardiovascular and thromboembolic complications [25].

\section{Selective estrogen receptor modulators}

These drugs are selectively connected with estrogen receptors in bones. They imitate the positive effect of estrogens on bone metabolism and at the same time they do not cause standard complications of estrogen treatment [25]. One of these drugs is raloxifene. Compared to placebo it causes a significant increase of bone density and decrease of bone resorption markers among patients with prostate cancer treated with anti-androgens [36].

Table 2. Review of studies concerning the efficacy of bisphosphonates in prevention of hormonal therapy induced bone loss

\begin{tabular}{|c|c|c|c|c|c|}
\hline \multirow[t]{2}{*}{ Author } & \multicolumn{2}{|c|}{ Number of patients } & \multirow[t]{2}{*}{ Treatment type } & \multicolumn{2}{|c|}{ Iverage $\%$ of $B M D$ changes after treatment } \\
\hline & tested group & control group & & lumbar spine & hip \\
\hline Smith (2001) [28] & 21 & 22 & $\begin{array}{l}\text { pamidronate } 60 \text { mg i.v. every } \\
12 \text { weeks (4 injections) vs. control group }\end{array}$ & 0.0 vs. -3.3 & 0.0 vs. -1.8 \\
\hline Smith (2003) [29] & 42 & 37 & $\begin{array}{l}\text { zoledronic acid } 4 \text { mg i.v. every } 3 \text { months } \\
\text { (4 injections) vs. placebo }\end{array}$ & 5.6 vs. -2.2 & 1.1 vs. -2.8 \\
\hline Ryan (2006) [30] & 50 & 51 & $\begin{array}{l}\text { zoledronic acid } 4 \text { mg i.v. every } 3 \text { months } \\
\text { (4 injections) vs. placebo }\end{array}$ & 4.6 vs. -2.1 & 1.4 vs. -2.4 \\
\hline Greenspan (2007) [31] & 56 & 56 & $\begin{array}{l}\text { alendronate } 70 \mathrm{mg} / \text { week, orally for } \\
1 \text { year vs. placebo }\end{array}$ & 3.7 vs. -1.4 & 0.7 vs. -0.7 \\
\hline Israeli (2007) [32] & 106 & 109 & $\begin{array}{l}\text { zoledronic acid } 4 \text { mg i.v. every } \\
3 \text { months ( } 4 \text { injections) vs. placebo }\end{array}$ & 4.7 vs. -2 & 1.6 vs. -2.1 \\
\hline Michaelson (2007) [33] & 22 & 22 & $\begin{array}{l}\text { zoledronic acid } 4 \text { mg i.v. one dose/year } \\
\text { vs. placebo }\end{array}$ & 4 vs. -3.1 & 0.7 vs. -1.9 \\
\hline
\end{tabular}




\section{New medicines}

Denosumab is an interesting drug that is an inhibitor of RANK-L receptor which strongly blocks the action of osteoclasts. Effectiveness of denosumab was proven in various prostate cancer stages: in early stages of the disease it prevents cancer treatment-induced bone loss (CTIBL) and in advanced stages it prevents cancer metastases to bones and bone complications of cancer. In a randomized study including a control group conducted on 1468 patients with prostate cancer with no metastases treated with hormone therapy, patients were given denosumab in a dose of $60 \mathrm{mg} / \mathrm{d}$ for 6 months. It was proven that denosumab significantly increased bone density (during a 2-year period: hip by $4.8 \%$, femoral neck by $3.9 \%$, lumbar spine by $6.7 \%, p<0.001$ ) and reduced the number of spine fractures by $62 \%$ in a 36 -month observation period compared to a placebo group [37].

Another randomized study compared the effectiveness of denosumab and zoledronic acid in preventing bone complications. The study included 1901 men with hormone-resistant prostate cancer and metastases to bones. Median patient age was 71 years. The endpoint of the study was skeletal-related events (SRE) defined by occurrence of: pathological fracture, metastases to bones requiring radiotherapy or surgery, or symptoms of spinal cord pressure. In patients treated with denosumab the symptoms occurred later than in patients treated with zoledronic acid (20.7 months vs. 17.1 months, $p=0.008$ ). Overall survival was similar in both groups [38].

\section{Monitoring}

According to $\mathrm{WHO}$ recommendations, in the case of introducing hormonal therapy to a patient with prostate cancer, regular tests should be performed to estimate bone density and the first test should be performed before therapy starts, while the next ones should take place on a regular basis (Table 3) [39]. A study retrospectively assessing the number of bone fractures after introducing hormonal therapy proved that only $13 \%$ of patients had densitometric tests performed and, what is interesting, over $50 \%$ of them had bone density lower than the level that meets the criteria of osteoporosis diagnosis [18].

Most authors suggest that each patient starting hormonal therapy should have their bone density checked and bone fracture risk factors defined in order to be classified in a particular risk group, which may steer further management [11, 25]. The risk of bone fractures in patients starting hormonal therapy is defined as high if one or more of the factors mentioned in Table 1 occurs.

Patients with no aforementioned factors are considered to be in a group of low bone fracture risk.

Table 3. Frequency of bone density examination

\begin{tabular}{|lcc|}
\hline Output value T-score & High risk of fracture & Low risk of fracture \\
\hline norm (to -1$)$ & 12 months & 24 months \\
\hline osteopenia $(-1$ to -2.5$)$ & 6 months & 12 months \\
\hline osteoporosis (more than -2.5$)$ & 6 months & 6 months
\end{tabular}

Measurement of bone density is usually performed on pelvic girdle bones or on lumbar vertebra. Two techniques with similar properties are used: DEXA (dual energy X-ray absorptiometry) or QCT (quantitative computed tomography). Despite advantages and disadvantages of the two techniques, it is important that each consecutive bone density measurement is performed with the same technique and on the same skeleton area - only then will the result present reliable differences in bone density. The possibilities of using bone resorption markers in monitoring patients are rarely taken advantage of in everyday clinical practice. However, evaluating these markers is easy to perform and potentially less expensive than bone density tests; hence the area requires further research [25].

\section{Metabolic disorders}

In a group of 79 patients it was shown that 12 -month hormonal therapy causes a weight increase of $1.8 \%$, an increase in body fat of $11 \%$ and a decrease in muscle mass by 3.8\% [40].

Male hypogonadism, regardless of etiology, always causes loss of muscle tissue mass and a simultaneous increase in the volume of adipose tissue. The observed changes are already noticeable after 3 months of anti-androgen therapy, increase with duration of treatment and are theoretically reversible after androgen supplementation [40, 41]. Reducing the concentration of testosterone results in the development of so-called sarcopenic obesity characterized by muscle atrophy and increase of body fat mass [11]. Next, it can lead to the development of metabolic syndrome characterized by abdominal obesity, hypertension, hyperglycemia, and dyslipidemia [42]. It was shown that the metabolic syndrome increases the risk of death from cardiac infarction, even in the absence of overt coronary artery disease [43]. Also having an effect on the development of obesity is a reduction of physical activity among patients with active anti-androgen treatment, which increases atrophy of muscle tissue. Skeletal muscles work as a regulator of blood glucose level and reduction of their weight causes a sharp increase in peripheral insulin resistance and accelerates the development of type 2 diabetes [11]. Some researchers believe that insulin resistance may be responsible for increased levels of adipocytokines (resistin, interleukin 6 , tumor necrosis factor $\alpha$ ) released from adipose tissue [40]. Hormonal therapy also leads to increased levels of total cholesterol, LDL and triglycerides. On the other hand, it often leads to an increase in HDL, so the impact of these changes on cardiovascular risk is unclear [40].

\section{Cardiovascular complications}

A Canadian study evaluating the long-term side effects of anti-androgen therapy was performed for more than 19 thousand patients with prostate cancer who were treated with hormonal therapy for at least 6 months [5]. The control group was selected for age, type of cancer treatment, comorbidities, medication use and risk factors for ischemic heart disease.

The average period of observation was 6.47 years. The endpoints adopted were prevalence of cardiac infarction, sudden cardiac death, diabetes or bone fractures. It was found that hormonal therapy significantly increases the risk of dia- 
betes progress among these patients (HR 1.16; 95\% Cl: 1.111.21). The value of NNH (number needed to harm - the number of patients whose treatment leads to one unfavorable endpoint) was 91, which means that diabetes will develop in 1 patient of 91 treated with hormonal therapy. The impact of concomitant hypertension on the incidence of diabetes was also revealed. It was also observed that the use of anti-androgenic drugs is associated with an increased risk of bone fractures ( $\mathrm{HR} 1.65 ; 95 \% \mathrm{Cl}: 1.53-1.77)$ and the risk increases with increasing duration of treatment. On the other hand, hormonal therapy does not affect the risk of coronary attack (HR 0.91; 95\% Cl: 0.84-1.0) or sudden cardiac death (HR 0.96; 95\% Cl: 0.83-1.1). The number of patients with cardiac infarction in the tested group was 1085 compared to 949 people in the control group. It is striking that in the group that applies hormonal therapy there occurred statistically significantly fewer brain strokes than in the control group (5.4\% vs. 6.4\%, $p=0.0001$ ) [5]. The controversy about the increased incidence of diabetes and the lack of growth in the number of cardiac infarction despite the fact that diabetes is a risk factor for cardiac infarction is explained by the fact that the impact of diabetes on appearance of infarction is long-term, so the 6-year observation period may have been too short to demonstrate this dependence.

Increased risk of cardiac infarction among patients with prostate cancer treated with hormonal therapy has been shown in studies conducted on only a few groups of patients. For example, D'Amico et al. [44] conducted a metaanalysis of three randomized trials in Australia, USA and Canada. The data were obtained from 1372 patients with prostate cancer aged 65 years or more. During the observation period that lasted, according to the study, from 4.6 to 6.7 years, only 51 deaths from cardiac infarction were noted. The number of these deaths was higher and these events occurred more rapidly in the group of patients treated with hormonal therapy (36 patients vs. 25 people, $p=0.017$ ). As a critique of the study, the lack of data of patients' concomitant diseases and presence of only one endpoint in the form of cardiac death are given. Saigal et al. conducted a similar study in a group of 4810 people with prostate cancer who were treated with hormonal therapy and 18006 people in the control group. Information on the patients was obtained from a medical database. The endpoint of the study, unlike in the study of d'Amico, assumed rates of heart diseases according to ICD 9 medical procedures. It was found that in the group of hormonal therapy treatment the risk of heart disease was higher by $20 \%$ compared to the control group [45]. It is an important fact that the coexistence of other risk factors for the development of coronary heart diseases such as diabetes, hypertension, and hyperlipidemia, which may significantly affect the result, were not evaluated.

Moreover, patients in the study group were older, aged even $>75$ years, and cancer in a more advanced stage was found more frequently in this population than in the control group, which also could have had an influence on the results of the experiment.

The most reliable evidence of an association between hormonal therapy and cardiovascular diseases was shown by Keating et al. for a group of 73196 people from the database of the SEER program, of whom $36.3 \%$ were treated with anti-androgens and $6.9 \%$ underwent orchidectomy. The average age was 74.2 years and the median period of observation 4.55 years.

Based on Cox regression, it was demonstrated that oral hormonal therapy was associated with an increased risk of diabetes (HR 1.44; $p<0.001)$, coronary heart disease (HR 1.16; $p<0.001)$, cardiac infarction (HR 1.11; $p<0.03)$, and sudden death from cardiac causes (HR 1.16; $p<0.004$ ). Orchidectomy only significantly increases the risk of diabetes (HR 1.34; $p<0.001)$. These discrepancies were explained by too small a group of patients after surgical castration [9]. It is also suggested that $\mathrm{GnRH}$ analogues may prolong the QT interval seen in the electrocardiogram, which promotes cardiac arrhythmias and may cause increased morbidity and mortality from cardiac causes in the group of patients who use oral hormonal therapy [46]

\section{Anemia}

Hormonal therapy reduces the concentration of hemoglobin in an indirect mechanism by $10 \%$ by reducing the concentration of testosterone, as it has been shown that androgens physiologically enhance erythropoiesis by increasing the production of erythropoietin and directly activate erythrocyte progenitor cells [17, 47].

\section{Summary}

Hormonal therapy for prostate cancer has increasing indications which should oblige doctors to familiarize themselves with the range of possible complications of the treatment.

This article describes the most common side effects of hormonal treatment and shows the possibility of accurate diagnosis in order to prevent and combat the adverse consequences of this therapy. The basic scope of research in the period of cancer patients' observation while using hormonal drugs should be expanded to routine measurement of blood pressure, body weight, abdomen circumference, cholesterol, triglycerides and glucose level. However, bone densitometry should be repeated $1-2$ years after the beginning of hormonal therapy.

The authors declare no conflict of interest.

\section{References}

1. Krajowy Rejestr Nowotworów. Available at: http://85.128.14.124/krn.

2. Meng MV, Grossfeld GD, Sadetsky N, Mehta SS, Lubeck DP, Carroll PR. Contemporary patterns of androgen deprivation therapy use for newly diagnosed prostate cancer. Urology 2002; 60: 7-11.

3. Borowka A, Dobruch J, Chłosta P. Leczenie hormonalne chorych na raka gruczołu krokowego. Przegl Urol 2011; 12: 23-32.

4. Sharifi N, Gulley JL, Dahut WL. Androgen deprivation therapy for prostate cancer. JAMA 2005; 294: 238-44.

5. Alibhai SM, Duong-Hua M, Sutradhar R, Fleshner NE, Warde P, Cheung AM, Paszat LF. Impact of androgen deprivation therapy on cardiovascular disease and diabetes. J Clin Oncol 2009; 27: 3452-8.

6. Greenspan SL, Coates P, Sereika SM, Nelson JB, Trump DL, Resnick NM.Bone loss after initiation of androgen deprivation therapy in patients with prostate cancer. J Clin Endocrinol Metab 2005; 90 : 6410-7. 
7. Shahinian VB, Kuo YF, Freeman JL, Goodwin JS. Risk of the "androgen deprivation syndrome" in men receiving androgen deprivation for prostate cancer. Arch Intern Med 2006; 166: 465-71.

8. Sanda MG, Dunn RL, Michalski J, et al. Quality of life and satisfaction with outcome among prostate-cancer survivors. N Engl J Med 2008; 358: 1250-61.

9. Keating NL, O'Malley AJ, Smith MR. Diabetes and cardiovascular disease during androgen deprivation therapy for prostate cancer. J Clin Oncol 2006; 24: 4448-56.

10. Schow DA, Renfer LG, Rozanski TA, Thompson IM. Prevalence of hot flushes during and after neoadjuvant hormonal therapy for localized prostate cancer. South Med J 1998; 91: 855-7.

11. Tombal B. A holistic approach to androgen deprivation therapy: treating the cancer without hurting the patient. Urol Int 2009; 83: 373-8.

12. Holzbeierlein JM. Managing complications of androgen deprivation therapy for prostate cancer. Urol Clin North Am 2006; 33: 181-90.

13. Mottet N, Prayer-Galetti T, Hammerer P, Kattan MW, Tunn U. Optimizing outcomes and quality of life in the hormonal treatment of prostate cancer. BJU Int 2006; 98: 20-7.

14. Knols R, Aaronson NK, Uebelhart D, Fransen J, Aufdemkampe G. Phys ical exercise in cancer patients during and after medical treatment: a systematic review of randomized and controlled clinical trials. $J$ Clin Oncol 2005; 23: 3830-42.

15. Shahinian VB, Kuo YF, Freeman JL, Goodwin JS. Risk of fracture after androgen deprivation for prostate cancer. N Engl J Med 2005; 352 154-64.

16. Smith MR, Lee WC, Brandman J, Wang Q, Botteman M, Pashos CL. Gonadotropin-releasing hormone agonists and fracture risk: a claims based cohort study of men with nonmetastatic prostate cancer. Clin Oncol 2005; 23: 7897-903.

17. Shahidi NT. Androgens and erythropoiesis. N Engl J Med 1973; 289: $72-80$.

18. Wilcox A, Carnes ML, Moon TD, Tobias R, Baade H, Stamos E, Elliott ME. Androgen deprivation in veterans with prostate cancer: implications for skeletal health. Ann Pharmacother 2006; 40: 2107-14.

19. Oefelein MG, Ricchuiti V, Conrad W, Seftel A, Bodner D, Goldman H, Resnick M. Skeletal fracture associated with androgen suppression induced osteoporosis: the clinical incidence and risk factors for patients with prostate cancer. J Urol 2001; 166: 1724-8.

20. Hatano T, Oishi Y, Furuta A, Iwamuro S, Tashiro K. Incidence of bone fracture in patients receiving luteinizing hormone-releasing hormone agonists for prostate cancer. BJU Int 2000; 86: 449-52.

21. Maxwell C, Viale PH. Cancer treatment-induced bone loss in patients with breast or prostate cancer. Oncol Nurs Forum 2005; 32: 589-603.

22. López AM, Pena MA, Hernández R, Val F, Martín B, Riancho JA. Frac ture risk in patients with prostate cancer on androgen deprivation therapy. Osteoporos Int 2005; 16: 707-11.

23. Oefelein MG, Ricchiuti V, Conrad W, Resnick MI. Skeletal fractures negatively correlate with overall survival in men with prostate cancer. J Urol 2002; 168: 1005-7.

24. Diamond T, Campbell J, Bryant C, Lynch W. The effect of combined androgen blockade on bone turnover and bone mineral densities in men treated for prostate carcinoma: longitudinal evaluation and response to intermittent cyclic etidronate therapy. Cancer 1998; 83: 1561-6.

25. Higano CS. Androgen-deprivation-therapy-induced fractures in men with nonmetastatic prostate cancer: what do we really know? Nat Clin Pract Urol 2008; 5: 24-34.

26. Smith MR, McGovern FJ, Fallon MA, Schoenfeld D, Kantoff PW, Finkelstein JS. Low bone mineral density in hormone-na?ve men with prostate carcinoma. Cancer 2001; 91: 2238-45.

27. Tang BM, Eslick GD, Nowson C, Smith C, Bensoussan A. Use of calcium or calcium in combination with vitamin D supplementation to prevent fractures and bone loss in people aged 50 years and old er: a meta-analysis. Lancet 2007; 370: 657-66.

28. Smith MR, McGovern FJ, Zietman AL, Fallon MA, Hayden DL, Schoenfeld DA, Kantoff PW, Finkelstein JS. Pamidronate to prevent bone loss during androgen-deprivation therapy for prostate cancer. N Engl J Med 2001; 345: 948-55.

29. Smith MR, Eastham J, Gleason DM, Shasha D, Tchekmedyian S, Zinner N. Randomized controlled trial of zoledronic acid to prevent bone loss in men receiving androgen deprivation therapy for nonmetastatic prostate cancer. J Urol 2003; 169: 2008-12.

30. Ryan CW, Huo D, Demers LM, Beer TM, Lacerna LV. Zoledronic acid initiated during the first year of androgen deprivation therapy increases bone mineral density in patients with prostate cancer. J Urol 2006; 176: $972-8$

31. Greenspan SL, Nelson JB, Trump DL, Resnick NM. Effect of once-week ly oral alendronate on bone loss in men receiving androgen deprivation therapy for prostate cancer: a randomized trial. Ann Intern Med 2007; 146: 416-24.

32. Israeli RS, Rosenberg SJ, Saltzstein DR, et al. The effect of zoledronic acid on bone mineral density in patients undergoing androgen deprivation therapy. Clin Genitourin Cancer 2007; 5: 271-7.

33. Michaelson MD, Kaufman DS, Lee H, McGovern FJ, Kantoff PW, FalIon MA, Finkelstein JS, Smith MR. Randomized controlled trial of annual zoledronic acid to prevent gonadotropin-releasing hormone agonist-induced bone loss in men with prostate cancer. J Clin Oncol 2007; 25: 1038-42.

34. Scherr D, Pitts WR Jr, Vaughn ED Jr. Diethylstilbestrol revisited: androgen deprivation, osteoporosis and prostate cancer. J Urol 2002; 167: 535-8.

35. Taxel P, Fall PM, Albertsen PC, Dowsett RD, Trahiotis M, Zimmerman J, Ohannessian C, Raisz LG. The effect of micronized estradiol on bone turnover and calciotropic hormones in older men receiving hormonal suppression therapy for prostate cancer. J Clin Endocrinol Metab 2002; 7: 4907-13.

36. Smith MR, Fallon MA, Lee H, Finkelstein JS. Raloxifene to prevent gonadotropin-releasing hormone agonist-induced bone loss in men with prostate cancer: a randomized controlled trial. J Clin Endocrinol Metab 2004; 89: 3841-6.

37. Smith MR, Egerdie B, Hernández Toriz N, et al.; Denosumab HALT Prostate Cancer Study Group. Denosumab in men receiving androgen-deprivation therapy for prostate cancer. N Engl J Med 2009; 361: 745-55.

38. Fizazi K, Carducci M, Smith $M$, et al. Denosumab versus zoledronic acid for treatment of bone metastases in men with castrationresistant prostate cancer: a randomised, double-blind study. Lancet 2011; 9768: 813-22.

39. Diamond TH, Higano CS, Smith MR, Guise TA, Singer FR. Osteoporosis in men with prostate carcinoma receiving androgen- deprivation therapy: recommendations for diagnosis and therapies. Cancer 2004; 100: 892-9.

40. Shahani S, Braga-Basaria M, Basaria S. Androgen deprivation therapy in prostate cancer and metabolic risk for atherosclerosis. J Clin Endocrinol Metab 2008; 93: 2042-9.

41. Basaria S, Wahlstrom JT, Dobs AS. Anabolic-androgenic steroid therapy in the treatment of chronic diseases. J Clin Endocrinol Metab 2001; 86: 5108-17.

42. Braga-Basaria M, Dobs AS, Muller DC, Carducci MA, John M, Egan J, Basaria S. Metabolic syndrome in men with prostate cancer undergoing long-term androgen-deprivation therapy. J Clin Oncol 2006; 24: 3979-83.

43. Lakka HM, Laaksonen DE, Lakka TA, Niskanen LK, Kumpusalo E, Tuomilehto J, Salonen JT. The metabolic syndrome and total and cardiovascular disease mortality in middle-aged men. JAMA 2002; 288: 2709-16.

44. D'Amico AV, Denham JW, Crook J, et al. Influence of androgen suppression therapy for prostate cancer on the frequency and timing of fatal myocardial infarctions. J Clin Oncol 2007; 25: 2420-5.

45. Saigal CS, Gore JL, Krupski TL, Hanley J, Schonlau M, Litwin MS; And the Urologic Diseases in America Project. Androgen deprivation therapy increases cardiovascular morbidity in men with prostate cancer. Cancer 2007; 110: 1493-500.

46. Garnick MB, Pratt CM, Campion M, Shipley J. The effect of hormonal therapy for prostate cancer on the electrocardiographic QT interval: Phase 3 results following treatment with leuprolide and goserelin, alone or with bicalutamide, and the $\mathrm{GnRH}$ antagonist abarelix. ASCO Annual Meeting Proceedings (Post-Meeting Edition). J Clin Oncol 2004; 22 (14S): 4578

47. Smith MR. Changes in fat and lean body mass during androgendeprivation therapy for prostate cancer. Urology 2004; 63: 742-5. 
Address for correspondence

\section{Ewa Ziółkowska}

Department of Radiotherapy I

Oncology Centre - prof. Franciszek Łukaszczyk Memorial Hospital

I. Romanowskiej 2

85-796 Bydgoszcz

e-mail: ziolkowskae@co.bydgoszcz.pl

Submitted: $\quad$ 19.06.2011

Accepted: $\quad 7.08 .2012$ 